\title{
Millimeter Wave Antenna for Intelligent Transportation Systems Application
}

\author{
N. Kishore, G. Upadhyay, A. Prakash, V. S. Tripathi \\ Department of Electronics \& Communication Engineering, \\ Motilal Nehru national Institute of Technology Allahabad, U.P., India \\ rel1353@mnnit.ac.in,rel1402@mnnit.ac.in,arun@mnnit.ac.in,vst@mnnit.ac.in
}

\begin{abstract}
A compact broadband millimeter wave antenna for intelligent transportation (ITS) application is proposed in this paper. This antenna uses coplanar wave guide feeding technique for broad bandwidth. The proposed antenna works at $79 \mathrm{GHz}$ resonant frequency having a large bandwidth of $78.2 \mathrm{GHz}$. The measured gain of the antenna is $17.5 \mathrm{dBi}$. The proposed antenna is very suitable for short range radar (SRR) application and \%G technologies.
\end{abstract}

Index Terms - Millimeter wave, ultra wide band, coplanar waveguide, defected ground, short range radar.

\section{INTRODUCTION}

Intelligent transportation system (ITS) is important part of human life and country. It supports human economy and helps in easily running of country. ITS have many applications lies in millimeter-wave frequency range like automotive radar applications and enabling wireless technologies. Automotive radar application is divided into two part like long range radar (LRR) and short range radar (SRR). Short range radar (SRR) system is a crucial element in automobile safety. It is responsible for detection and prevention of potential collisions. Thus, helps in reducing the number and severity of road accidents. It has many more applications like, pre crash sensing / control firing of restraints, airbags / break boosting, stop and go functionality, lane change warning, lane change aid, blind spot detection, parking aid and back drive assistance [1] [2]. Fig.1 shows the coverage area of automotive radar antenna. Short range radar has four types: continuous wave $(\mathrm{CW})$ radar, frequency modulated continuous wave (FMCW) radar, synthetic aperture radar (SAR), phased array radar, and ultra wide band (UWB) impulse radar. Small CW Doppler radar systems are used as motion sensors and for measuring the speed of automobiles. FMCW radar is used for radar altimeters in aircrafts. SAR is developed for airborne ground mapping at a stand-off distance. Phased array radar is used for imaging system. The millimeter wave antenna is used for short range radar application [3]. The SRR for automotive application has three centre frequencies $-24.5 \mathrm{GHz}, 26.5 \mathrm{GHz}$, and $79 \mathrm{GHz}$. Their respective bandwidths are $5 \mathrm{GHz}, 4 \mathrm{GHz}$, and $4 \mathrm{GHz}$ respectively [4]. 5G is one the enabling technologies that works in millimeter-wave frequency range. It works in the frequency range of 24 GHz to $86 \mathrm{GHZ}$ [5].

This paper focuses on design and development of millimeter wave antenna for intelligent 
transportation systems (ITS) application. This paper focuses on the safety and connectivity applications of vehicles. For safety application $79 \mathrm{GHz}$ is the centre frequency [6] and for connectivity $5 \mathrm{G}$ technologies used.

A $79 \mathrm{GHz}$ millimeter wave automotive radar front-end with monolithic microwave integrated circuit (MMIC) technology having bandwidth of $9.05 \mathrm{GHz}$ and gain of $6.5 \mathrm{dBi}$ is discussed in [7]. A $79 \mathrm{GHz}$ millimeter wave antenna based on a conformal waveguide with slot array having $15.7 \mathrm{dBi}$ gain is discussed in [8]. A $77 \mathrm{GHz}$ frequency modulated continuous-wave (FMCW) radar system having bandwidth of $6 \mathrm{GHz}$ and gain of $10 \mathrm{dBi}$ is discussed in [9].

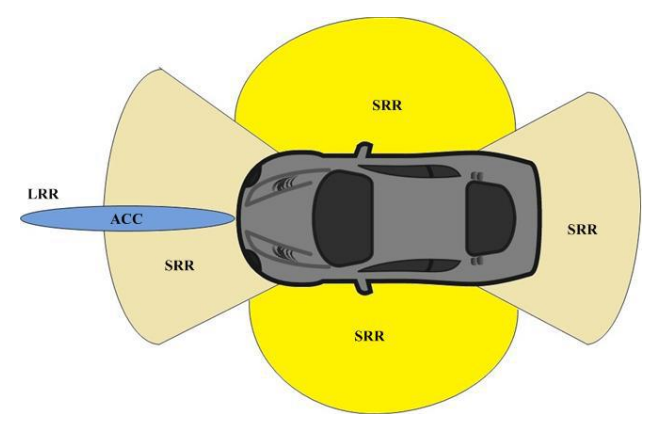

Fig. 1. Placement and coverage area of automotive radar antenna [10].

A $79 \mathrm{GHz}$ patch antenna array for short range radar system having bandwidth of $9.6 \mathrm{GHz}$ and gain of $14.5 \mathrm{dBi}$ is discussed in [11]. A $77 \mathrm{GHz}$ electronically beam-steerable integrated lens millimeter wave antenna having bandwidth of $35 \mathrm{GHz}$ is discussed in [12]. A $77 \mathrm{GHz}$ Yagi-Uda antenna for automotive radar sensor having gain of $15.8 \mathrm{dBi}$ is discussed in [13]. A $77 \mathrm{GHz}$ and $94 \mathrm{GHz}$ millimeter wave radar system having bandwidth of $2 \mathrm{GHz}$ and $4.9 \mathrm{GHz}$ respectively is discussed in [14]. A $77 \mathrm{GHz}$ multi-channel directional folded dipole radar antenna having gain of $8.2 \mathrm{dBi}$ is discussed in [15]. A $77 \mathrm{GHz}$ lens antenna for automotive radar having bandwidth of $4 \mathrm{GHz}$ is proposed in [16]. A $77 \mathrm{GHz}$ millimeter wave technology for automotive radar sensors having bandwidth of $4 \mathrm{GHz}$ and half power beam width gain of $5 \mathrm{dBi}$ is discussed in [17]. A $77 \mathrm{GHz}$ microelectromechanical systems based active phase shifter for $\mathrm{W}$-band automotive radar having gain of 14 $\mathrm{dBi}$ is proposed in [18]. A 76-77GHz radar having gain of $14.2 \mathrm{dBi}$ is discussed in [19]. A microstrip grid array antenna for millimeter wave frequencies having centre of $60 \mathrm{GHz}$ and bandwidth of $5 \mathrm{GHz}$ with gain $14 \mathrm{dBi}$ is reported in [20]. A $60 \mathrm{GHz}$ printed millimeter array antenna for millimeter wave application is discussed in [21]. A cavity back antenna works in frequency range of $28 \mathrm{GHz}$ to 60 $\mathrm{GHz}$ for millimeter wave application is discussed in [22]. A substrate integrated dielectric resonator antenna having centre frequency for millimeter wave application is reported in [23]

These antennas have relatively lower bandwidth and gain. In this paper, an antenna with very large bandwidth and high gain is proposed. A novel antenna design is proposed based on defected ground structure. Optimization is done to get best design parameters for proposed antenna. It is also circularly polarized and hence, it can be used as millimeter wave antenna for short range radar application. The proposed antenna is fabricated in the lab. The validation of proposed antenna is done by both 
simulation and experimental methods. The Simulated and experimental results match very well.

This paper is organized as follows: section II shows design specifications of proposed antenna. Section III shows simulation result and discussion. The conclusion is presented in section IV.

\section{DESIGN SPECIFICATION}

In this section we discuss the structure of proposed antenna and its design procedure. In order to get high centre frequency the size of the antenna should be small and dielectric constant of substrate should be high. In proposed antenna design coupling of energy between the coplanar wave guides feed line and square patch yields resonance at desired centre frequency. Further, the energy coupling between coplanar wave guide feed line and defected ground structure results in a very large bandwidth.

The structure of proposed antenna is shown in Fig.2. The top view of the proposed antenna structure is shown in Fig.2 (a).

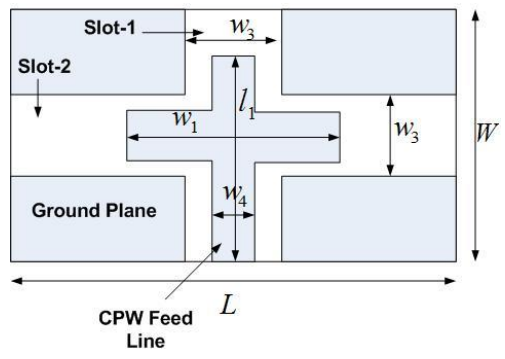

(a)

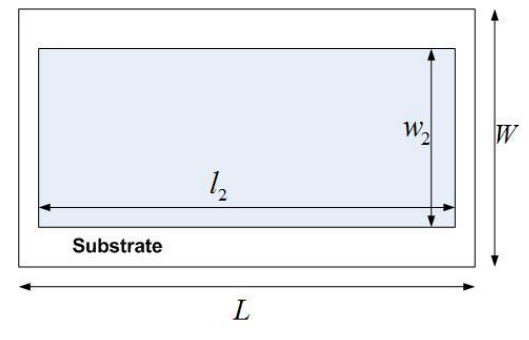

(b)

Fig. 2 Proposed antenna structure shows (a) top view and (b) bottom view.

The top view of the proposed antenna structure shows the defected ground plane with CPW feed line in Fig.2 (a). There are two slots in the ground plane each having width $w_{3}$. The length of the feed line is $l_{1}$ and its arm length is $w_{1}$. The width of the feed line is $w_{4}$. Bottom view shows copper plane in Fig. 2 (b) having dimension of $l_{2} \times w_{2}$. The substrate material used is Roger 3210 having dielectric constant 10.2 with height $1.28 \mathrm{~mm}$. The length and width of substrate are $L$ and $W$ respectively. The antenna is simulated using HFSSv18 [24]. The values of parameters are given in Table I.

TABLE I. VALUES OF PARAMETERS (IN MM)

\begin{tabular}{ccccccccc}
\hline Parameter & $L$ & $W$ & $l_{1}$ & $w_{1}$ & $l_{2}$ & $w_{2}$ & $w_{3}$ & $w_{4}$ \\
\hline Value & 24 & 14 & 11 & 8 & 18 & 10 & 4 & 2 \\
\hline
\end{tabular}

\section{RESUlT AND DisCUSSION}

Fig.3 shows the simulated result of return loss by varying the length and width of the patch of proposed antenna structure. Fig.4 shows the simulated result of return loss by varying the parameters of feed line and ground slots. The results are shown in Table II.

It shows the parametric analysis of proposed antenna structure. From parametric analysis the values of the parameters are chosen which are best fit at $79 \mathrm{GHz}$ centre frequency. The details of Brazilian Microwave and Optoelectronics Society-SBMO received 04 Nov2017; for review 09 Nov 2017; accepted 13 March 2018 
optimization are shown in Table II.

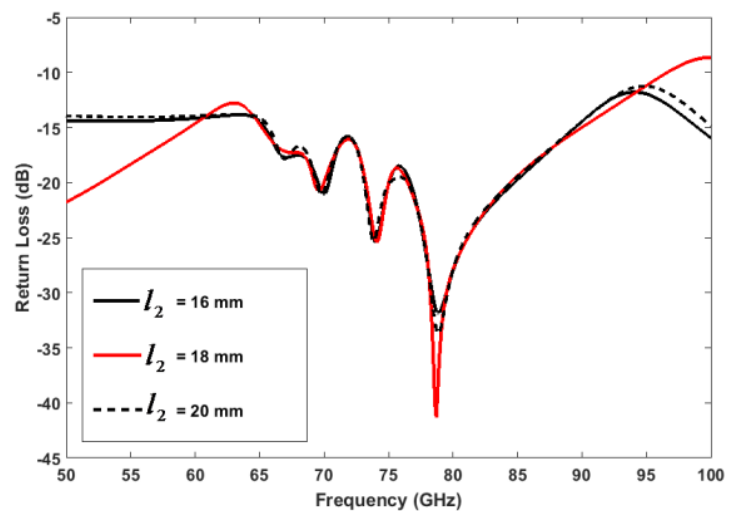

(a)

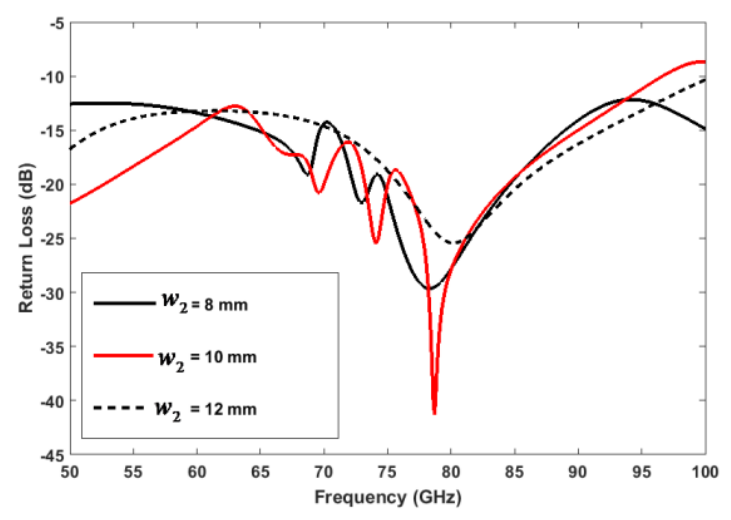

(b)

Fig. 3. Simulated return loss in $\mathrm{dB}$ by (a) variation in length of bottom plane $l_{2}$ and (b) variation in width of bottom plane $w_{2}$.

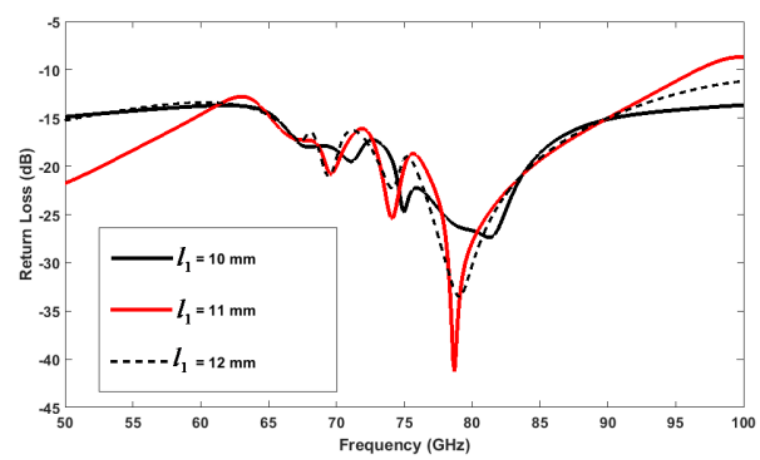

(a)

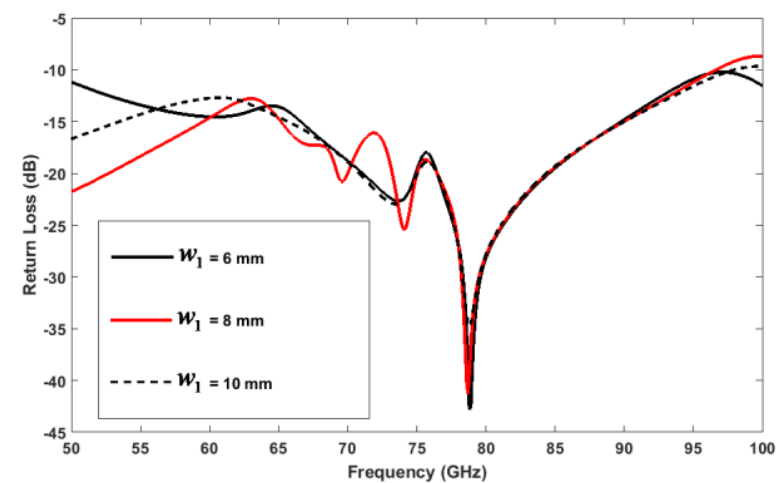

(b)

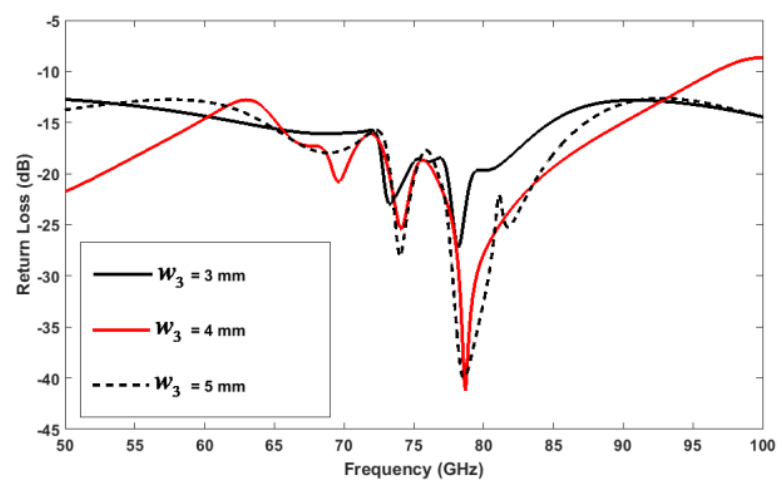

(c)

Fig. 4. Simulated return loss in $\mathrm{dB}$ by (a) variation in length of feed line $l_{1}$, (b) variation in length of arm of feed line $w_{1}$ and (c) variation in width of slots of the ground plane $w_{2}$.

TABLE II. RETURN LOSS RESULTS DATA BY VARYING PARAMETERS

\begin{tabular}{ccccc}
\hline Parameter & $\begin{array}{c}\text { Values } \\
\text { (in mm) }\end{array}$ & $\begin{array}{c}\text { Centre Frequency } \\
\text { (in GHz) }\end{array}$ & $\begin{array}{c}\text { Return loss } \\
\text { (in dB) }\end{array}$ & $\begin{array}{c}\text { Bandwidth below } \\
\text {-20dB return loss (in GHz) }\end{array}$ \\
\hline \multirow{2}{*}{$l_{1}$} & 10 & 81.3 & -27.27 & 10 \\
& 11 & 79 & -41.29 & 8.1 \\
& 12 & 79.1 & -33.37 & 8.7 \\
\hline \multirow{2}{*}{$w_{1}$} & 6 & 78.8 & -42.78 & 8.2 \\
& 8 & 79 & -41.29 & 8.1 \\
\hline$l_{2}$ & 10 & 78.8 & -34.8 & 8.2 \\
\hline
\end{tabular}




\begin{tabular}{ccccc} 
& 18 & 79 & -41.29 & 8.1 \\
& 20 & 78.9 & -33.68 & 8.2 \\
\hline \multirow{3}{*}{$w_{2}$} & 8 & 78.3 & -29.64 & 10.1 \\
& 10 & 79 & -41.29 & 8.1 \\
& 12 & 80.2 & -25.44 & 9.6 \\
\hline \multirow{3}{*}{$w_{3}$} & 3 & 78.1 & -27.08 & 2 \\
& 4 & 79 & -41.29 & 8.1 \\
& 5 & 78.6 & -40.09 & 7.4 \\
\hline
\end{tabular}

The prototype of antenna is shown in Fig.5. The proposed antenna structure is fabricated and tested in the laboratory. The prototype antenna is connected with keysight $11500 \mathrm{~J}$ test port cable and tested with keysight N5250A-017 PNA millimeter-wave network analyzer. The simulated and measured results for return loss are shown in Fig.6. It is noted that the measured and simulated results match very well. The observed centre frequency is $79 \mathrm{GHz}$. The measured value of the return loss is -40.9 $\mathrm{dB}$. The measured bandwidth is $78.2 \mathrm{GHz}$ below $-10 \mathrm{~dB}$ return loss having band range of $18.1 \mathrm{GHz}-$ $96.3 \mathrm{GHz}$.

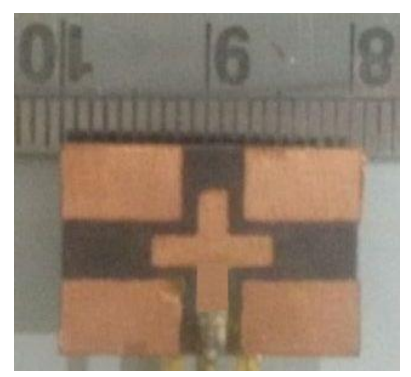

(a)

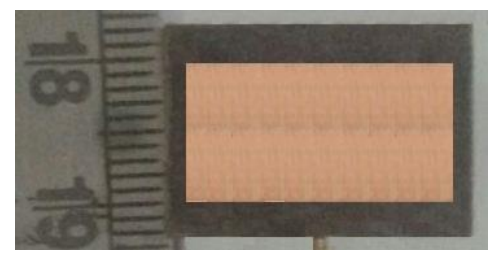

(b)

Fig. 5. Prototype of proposed antenna shows (a) top view and (b) bottom view

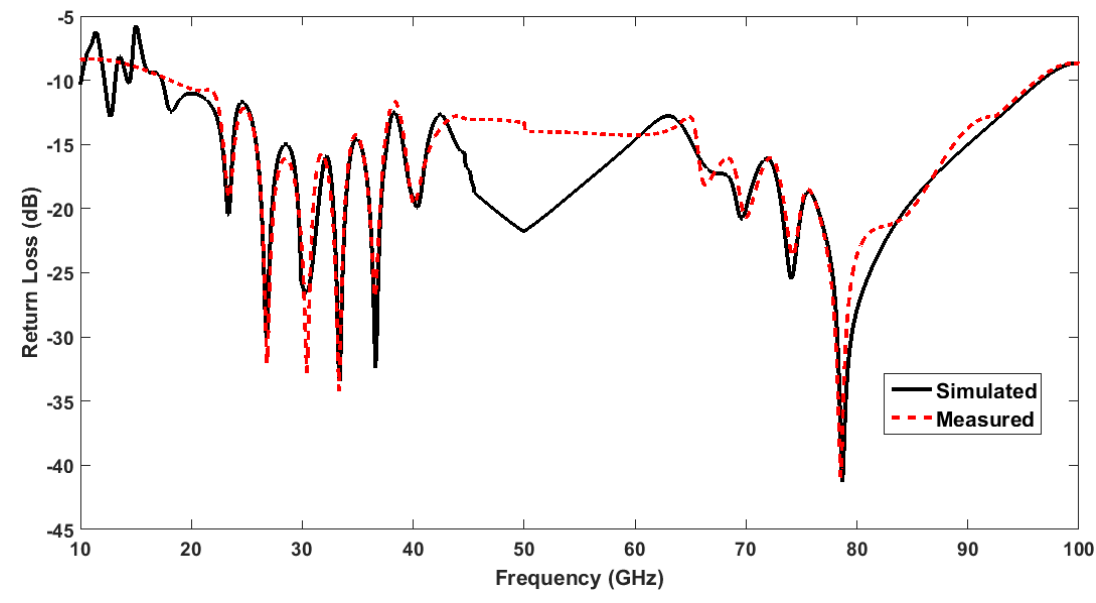

Fig. 6. Simulated and measured result of return loss of the proposed antenna structure.

The vector current distribution of proposed antenna is shown in Fig.7. This figure shows that there is energy coupling between the feed line and the defected ground structure. This coupling of energy produces very low value of capacitance and inductance of the antenna. The low value of capacitance and inductance produces high value of centre frequency. There is also coupling of energy between the 
feed line and bottom plane. This helps in the impedance matching, which in turn produces the desired centre frequency. Due to coupling, this antenna produces a very wide bandwidth

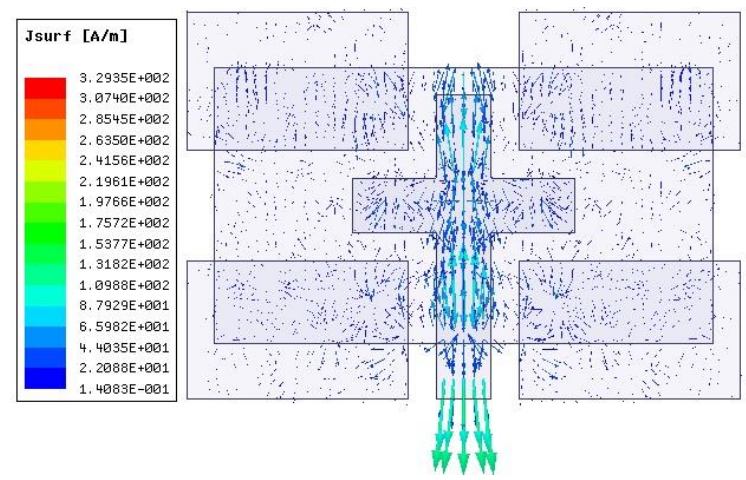

Fig. 7. Current distribution on the proposed antenna structure.

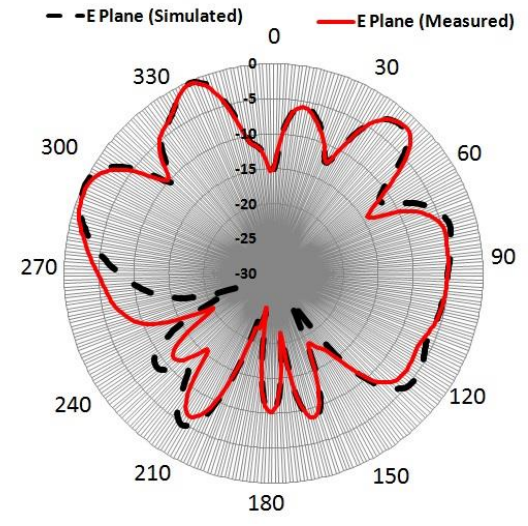

(a)

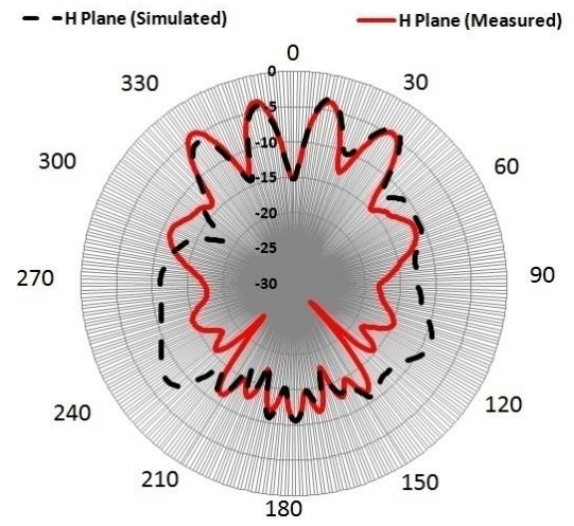

(b)

Fig. 8. Simulated and measured result of radiation pattern (a) E plane, and (b) $\mathrm{H}$ plane

The simulated and measured radiation pattern results are shown in Fig.8. The simulated and measured results of E Plane and H Plane are shown in Fig.8. It can be observed that E plane radiation of proposed antenna covers broad range while $\mathrm{H}$ plane has less backward radiation and covers small range with high gain value.

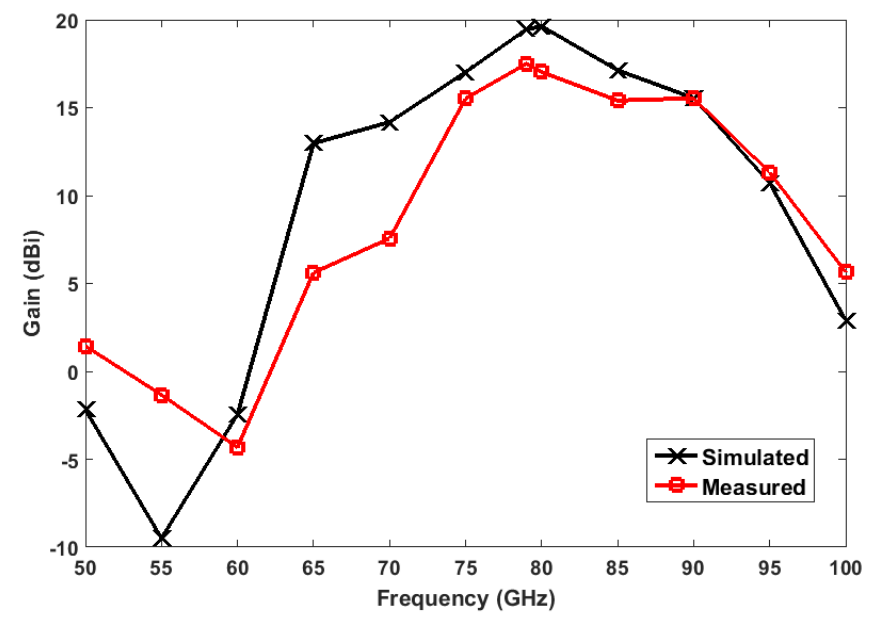

Fig. 9. Simulated and measured gain in dBi. 
The proposed antenna produces high gain as shown in Fig.9. The simulated and measured gains of the antenna are $19.46 \mathrm{dBi}$ and $17.5 \mathrm{dBi}$ respectively. This shows that antenna is suitable for automotive radar system.

TABLE III. COMPARISON OF RECENTLY PUBLISHED WORK ON MILLIMETER WAVE ANTENNA WITH PROPOSED WORK

\begin{tabular}{|c|c|c|c|c|}
\hline Parameter & $\begin{array}{c}\text { Abdellatif et.al. } \\
\mathbf{2 0 1 5}[\mathbf{1 1}]\end{array}$ & $\begin{array}{c}\text { You Chao Tu et.al. } \\
\mathbf{2 0 1 6}[\mathbf{2 5}]\end{array}$ & $\begin{array}{c}\text { Yujian Li et.al. } \\
\mathbf{2 0 1 7}[\mathbf{2 6}]\end{array}$ & Proposed Work \\
\hline Centre Frequency & $79 \mathrm{GHz}$ & $35 \mathrm{GHz}$ & $34 \mathrm{GHz}$ & $79 \mathrm{GHz}$ \\
\hline Bandwidth & $9.6 \mathrm{GHz}$ & $8.75 \mathrm{GHz}$ & $13.5 \mathrm{GHz}$ & $78.2 \mathrm{GHz}$ \\
\hline Gain & $14.5 \mathrm{dBi}$ & $4.6 \mathrm{dBi}$ & $13.6 \mathrm{dBi}$ & $17.45 \mathrm{dBi}$ \\
\hline
\end{tabular}

Further, a comparison of results of proposed work with newly reported antenna is shown in Table III. It is noted that the proposed antenna gives better result than the reported antenna. The proposed antenna is suitable for SRR in ITS applications.

\section{CONCLUSION}

The proposed antenna gives a very wide band range of $18.1 \mathrm{GHz}$ to $96.3 \mathrm{GHz}$. The measured bandwidth of proposed antenna structure is $78.2 \mathrm{GHz}$. The proposed antenna is circularly polarized in nature. In this paper parametric analysis of proposed antenna is also discussed. The measured and simulated results match very well. The prototype of antenna has very high gain of $17.5 \mathrm{dBi}$. High gain, large and bandwidth of antenna make it suitable for intelligent transportation application.

\section{REFERENCES}

[1] R. Bishop, “Application Areas”, in Intelligent Vehicle Technology and Trends, Artech House ITS Library, pp. 25 - 37 , 2005.

[2] R. Lachner, "Development Status of Next Generation Automotive Radar in EU”, ITS Forum, Tokyo, 2009.

[3] G. L. Charvat, "Small and Short-Range Radar Systems", CRC Press, 2014.

[4] A. Kajiwara, "UltraWideband Automotive Radar",in Advances in Vehicular Networking Technologies, pp. 103 - 122, 2011.

[5] https://www.rfpage.com/applications-of-millimeter-waves-future/(Date-05/02/2018)

[6] ITU-R WP 5A/B, "Intelligent transport systems (ITS)", Radiocommunication Study Groups, International Telecommunication Union, 2015.

[7] D. Platt, L. Pettersson, D.Jakonis et al. "Integrated 79GHz UWB Automotive Radar Front- End based on Hi-Mission MCM-D Silicon Platform", Proceedings of the 6th European Radar Conference, pp. 445 - 448, 2009.

[8] H. Iwai, S.Suetsugu et al., "Feasibility Study on a Slot Array in the Millimeter-Wave Band Based on a Conformal Waveguide", International Symposium on Antennas and Propagation (ISAP),vol. 5, pp. 1- 3, 2015.

[9] A. Melzer, A. Onic, F. Starzer,and M. Huemer, "ShortRange Leakage Cancelation in FMCW Radar Transceivers Using an Artificial On- Chip Target", IEEE Journal of Selected Topics in Signal Processing, vol. 9, no. 8, pp. 1650 - 1660 , 2015.

[10] Jau-Jr Lin, "Analysis and Design of the Switched-beam Antenna Array for Automotive Radar Applications", Progress In Electromagnetics Research Symposium Proceedings, pp. 2561 - 2564, 2014.

[11] A. Abdellatif, M. Ghassemi et al., "Low Cost Low Loss Waveguidefed Patch Antenna Array for Automotive Radar System", Global Symposium on Millimeter Waves (GSMM), pp. 1 - 3, 2015.

[12] A. Artemenko, A. Mozharovskiy et al., "Experimental Characterization of E-Band Two-Dimensional Electronically Beam-Steerable Integrated Lens Antennas”, IEEE Antennas and Wireless Propagation Letters, vol. 12, pp. 1188 1191, 2013.

[13] S. Beer, G. Adamiuk,and T. Zwick, "Novel Antenna Concept for Compact Millimeter-Wave Automotive Radar Sensors", IEEE Antennas and Wireless Propagation Letters, vol. 12, pp. 771 - 774, 2009.

[14] G. M. Brooker, "Mutual Interference of Millimeter-Wave Radar Systems", IEEE Transactions on Electromagnetic Compatibility, vol. 7, no. 1, pp. 170 - 181, 2007.

[15] A. Fischer, Z. Tong et al., "77-GHz Multi-Channel Radar Transceiver With Antenna in Package", IEEE Transactions on Antennas And Propagation, vol. 62, no. 3, pp. 1386 - 1393, 2014.

[16] P. Hallbjrner, Z. He, S. Bruce, and S. Cheng, "Low-Profile 77-GHz Lens Antenna With Array Feeder", IEEE Antennas and Wireless Propagation Letters, vol. 11, pp. 205 - 207, 2012. 
[17] J. Hasch, E. Topak et al., "Millimeter-Wave Technology for Automotive Radar Sensors in the 77 GHz Frequency Band", IEEE Transactions on Microwave Theory and Techniques, vol. 60, no. 3, pp. 845 - 860, 2012.

[18] E. Ozturk, M. H.Nemati et al., "SiGe Process Integrated Full360 Microelectromechanical SystemsBased Active Phase Shifter for W-Band Automotive Radar", IET Microwaves, Antennas and Propagation, pp. 835 - 841, 2014.

[19] M. Chen, C. C. Chen, S. Y. P. Chien, and R. Sherony, "Artificial Skin for 76-77 GHz Radar Mannequins", IEEE Transactions on Antennas and Propagation, vol. 62, no. 11, pp. 5671 - 5679, 2014.

[20] B. Zhang and Y. P. Zhang, "Analysis and Synthesis of Millimeter-Wave Microstrip Grid-Array Antennas", IEEE Antennas and Propagation Magazine, vol. 53, no. 6, pp. 42 - 55, December 2011.

[21] Aleksandar D. Nesic and Dusan A. Nesic, "Printed Planar 8x8 Array Antenna with Circular Polarization for MillimeterWave Application", IEEE Antennas and Wireless Propagation Letters, vol. 11, pp. 744 - 747, 2012.

[22] Shi-Wei Qu and Kung Bo Ng, "Millimeter-Wave Bowtie Excited Cavity-Backed Antenna with Improved Aperture", IEEE Antennas and Wireless Propagation Letters, vol. 11, pp. 697 - 700, 2012.

[23] Abdolmehdi Dadgarpour, Behnam Zarghooni, Bal S.Virdee, and Tayeb A.Denidni, "Millimeter-Wave High-Gain SIW End-Fire Bow-tie Antenna", IEEE Transactions on Antennas and Propagation, vol. 63, no. 5, pp. 2337 - 2342, May 2015.

[24] ANSYS Academic Research, Release 15.0.

[25] You Chao Tu, Dong Dong Ma, Yan Liu, Xue Rui Ru, and Ke Gong, "Broadband Substrate Integrated Dielectric Resonator Antenna for Millimeter-Wave Applications", IEEE MTT-S International Microwave Workshop Series on Advanced Materials and Processes for RF and THz Applications (IMWS-AMP), pp. 1 - 3, 20-22 July 2016.

[26] Yujian Li, Jingxue Wang and Junhong Wang, "Millimeter-Wave Wideband Substrate Integrated Waveguide Horn Antenna Loaded with Dipole Array", International Workshop on Electromagnetics: Applications and Student Innovation Competition, pp. 12 - 13, 30 May - 1 June 2017. 